\title{
PEMBUATAN PROGRAM APLIKASI LAPORAN PERAWATAN KOREKTIF LABORATORIUM PEMESINAN POLMAN BABEL
}

\author{
Zaldy Sirwansyah Suzen ${ }^{1}$, Indra Feriadi ${ }^{2}$ \\ ${ }^{1,2}$ Jurusan Teknik Mesin - Politeknik Manufaktur Negeri Bangka Belitung \\ Kawasan Industri Airkantung Sungailiat-Bangka, 33211 \\ Tel: 0717-93586, Fax: 0717-93585, Syahdika99@gmail.com
}

\begin{abstract}
Politeknik Manufaktur Negeri Bangka Belitung is university that provide education and training in the field of engineering where there are machinery and equipment as a means of learning. The good maintenance of machine and equipment is the most important to support the learning activities. However the bad maintenance will cause disadventages for company benefit. During this time corrective maintenance is handled in a manual that is recorded in books that causes data repairing of machine is not documented well. Based on this improvement and maintenance of existing system development should be pursued in order to improve the administration system of care maintenance. The system design is oriented for creation of database applications that are expected to solve the problem.
\end{abstract}

Keyword: Database, damage report, corrective maintenance

\begin{abstract}
Abstrak
Politeknik Manufaktur Negeri Bangka Belitung merupakan perguruan tinggi negeri yang menyelenggarakan pendidikan dan pelatihan di bidang keteknikan dimana terdapat mesin dan peralatan sebagai sarana pembelajaran. Perawatan mesin dan peralatan yang baik merupakan suatu hal yang sangat penting dalam mendukung aktifitas pembelajaran. Pengelolaan administrasi perawatan yang kurang baik akan menyebabkan kerugian-kerugian yang tidak terhindarkan sehingga investasi yang ditanamkan dengan maksud untuk jangka panjang dan mendapatkan keuntungan akan berakibat sebaliknya. Selama ini aktifitas perawatan terutama laporan kerusakan pada perawatan korektif masih ditangani dengan cara manual yaitu mencatat di buku tulis yang menyebabkan data-data laporan perawatan dan perbaikan mesin tidak terdokumentasi dengan baik. Atas dasar inilah perbaikan dan pengembangan sistem perawatan yang ada perlu diupayakan dalam rangka memperbaiki sistem dokumentasi laporan perawatan korektif permesinan. Rancangan sistem ini diorientasikan pada pembuatan program aplikasi database laporan perawatan korektif yang diharapkan nantinya bisa membantu mengatasi permasalahan yang ada.
\end{abstract}

Kata kunci : database, laporan kerusakan, corrective maintenance

\section{PENDAHULUAN}

Politeknik Manufaktur Negeri Bangka Belitung (Polmanbabel) merupakan perguruan tinggi negeri yang mempunyai misi menyelenggarakan pendidikan dan pelatihan secara efektif dan efisien untuk pasar tenaga kerja di tingkat nasional dan menghasilkan tenaga ahli terutama di bidang keteknikan yang terampil, mampu bekerja dengan baik dan dapat diterima internasional. Politeknik ini memiliki 3 (tiga) program studi yang salah satunya program studi Teknik Perawatan dan Perbaikan Mesin. Program studi ini memiliki laboratorium pemesinan yang dilengkapi dengan fasilitas mesin-mesin manufaktur sebagai penunjang kegiatan pendidikan seperti mesin bubut, freis, bor, skrap, CNC, gerinda datar dan silinder.

Semenjak berdiri pada tahun 1994, metode perawatan perbaikan yang diterapkan pada Laboratorium Pemesinan Polmanbabel saat ini adalah perawatan korektif. Kondisi mesin dan peralatan yang siap pakai merupakan suatu hal yang sangat penting bagi politeknik, dimana mesin dan peralatan tersebut akan dipergunakan seluruh mahasiswa sebagai sarana untuk praktik perkuliahan dan produksi. Oleh karena itu aktifitas perawatan ini harus benar-benar diperhatikan karena akan mempengaruhi kinerja bagi keberlangsungan kegiatan perkuliahan seluruh program studi.

Pelaksanaan laporan perawatan yang kurang baik, seperti tidak dilakukannya kegiatan administratif yang baik akan menyebabkan kerugian-kerugian yang tidak terhindarkan sehingga investasi 
yang telah ditanamkan dengan maksud untuk mendapatkan keuntungan dan memberikan manfaat yang besar akan berakibat sebaliknya.

Perawatan diartikan sebagai serangkaian tindakan, baik teknik maupun administratif, yang diperlukan untuk menjaga suatu barang berada pada kondisi operasionalnya yang efektif [1].

Secara definisi dikatakan bahwa perawatan adalah suatu kombinasi dari semua tindakan yang dilakukan dalam rangka mempertahankan atau mengembalikan suatu peralatan pada kondisi yang dapat diterima. Perawatan terencana dibagi menjadi dua aktivitas utama yaitu perawatan pencegahan dan Perawatan Korektif [2].

Perawatan korektif adalah perawatan yang dilakukan secara berulang atau perawatan yang dilakukan untuk memperbaiki suatu bagian (termasuk penyetelan dan reparasi) yang telah terhenti untuk memenuhi suatu kondisi yang bisa diterima. Perawatan ini meliputi reparasi minor, terutama untuk rencana jangka pendek, yang mungkin timbul diantara pemeriksaan, juga overhaul terencana [2].

Perbedaan utama antara perawatan perbaikan dan pencegahan adalah bahwa masalah yang ada harus dilakukan sebelum tindakan koreksi. Tugas perawatan preventif yang dimaksudkan adalah untuk mencegah terjadinya masalah. Sedangkan tugas korektif yaitu memperbaiki masalah yang ada. Tujuan dari tugas terencana hanya untuk mempertahankan semua mesin pabrik yang kritis dan sistem dalam kondisi operasi yang optimal [3].

Untuk menerapkan fungsi perawatan yang baik selain melaksanakan hal-hal yang bersifat teknis tak kalah pentingnya juga harus senantiasa melakukan kegiatan-kegiatan administratif dengan tertib. Data-data perawatan terutama perawatan korektif merupakan sesuatu yang sangat penting dalam mengendalikan kegiatan perawatan karena informasi yang kita butuhkan seperti rencana perawatan, riwayat kerusakan, kapan mesin perbaikan dan apa suku cadang yang diganti merupakan dasar penentuan kebijakan perawatan yang akan diambil. Sedemikian pentingnya kegiatan ini sudah selayaknya harus mendapat perhatian yang besar. Pemanfaatan komputer untuk pelaksanaan kegiatan ini diharapkan sangat membantu karena kemudahan-kemudahan yang disediakan akan banyak memangkas waktu yang diperlukan dalam melakukan kegiatan ini bila dibandingkan dengan cara-cara manual.

\section{METODE PENELITIAN}

Dalam melaksanakan penelitian ini maka diperlukan langkah-langkah yang sistematis sehingga hasil yang diinginkan dapat tercapai. Langkah-langkah penelitian dilakukan dengan maksud agar kegiatan penelitian lebih terarah serta memudahkan dalam pembuatan rancangannya dapat dilihat pada Gambar 1.

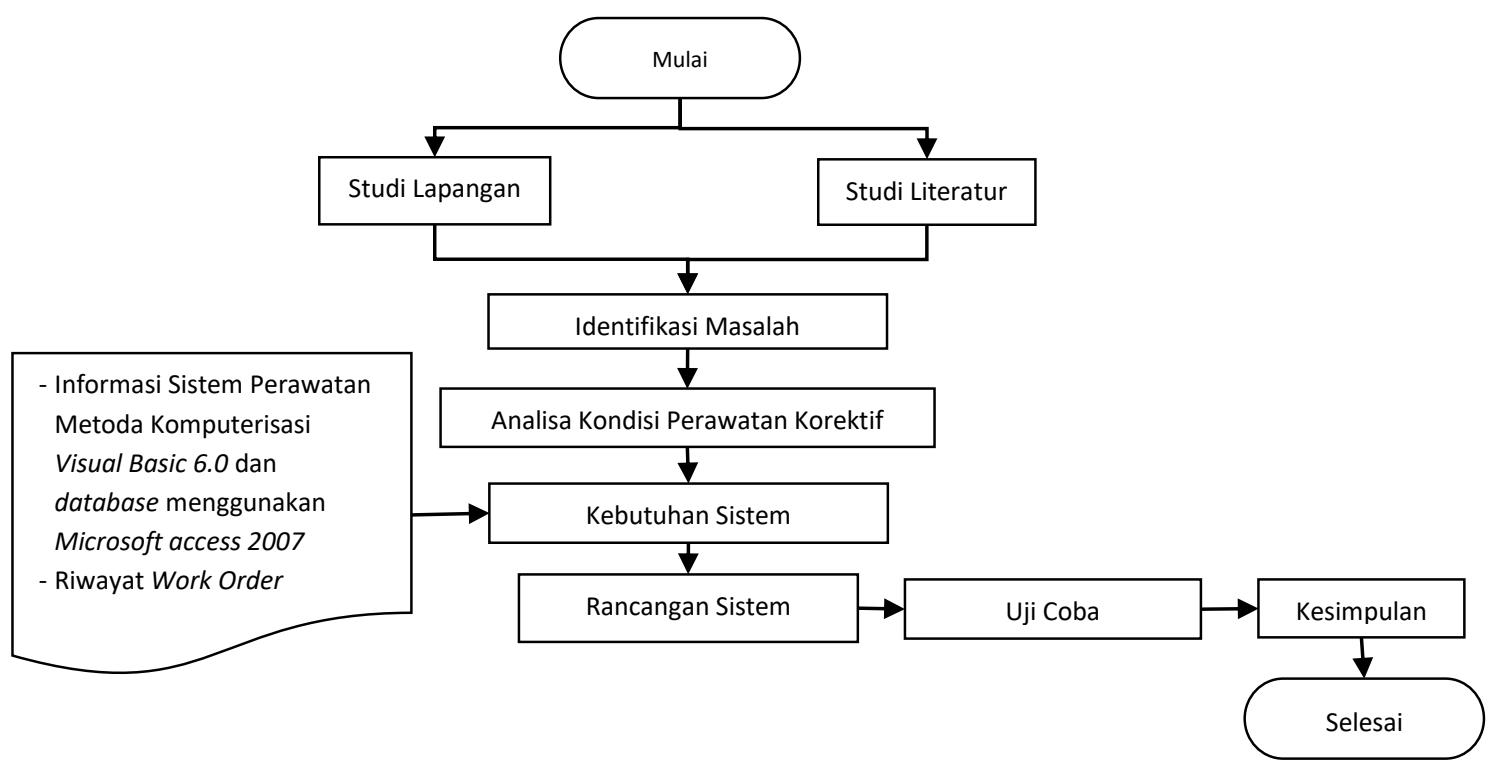

Gambar 1. Flow chart Langkah-langkah Penelitian 
Adapun pelaksanaan perawatan perbaikan pada saat ini terlihat pada gambar diagram alir yang ditunjukkan pada Gambar 2.

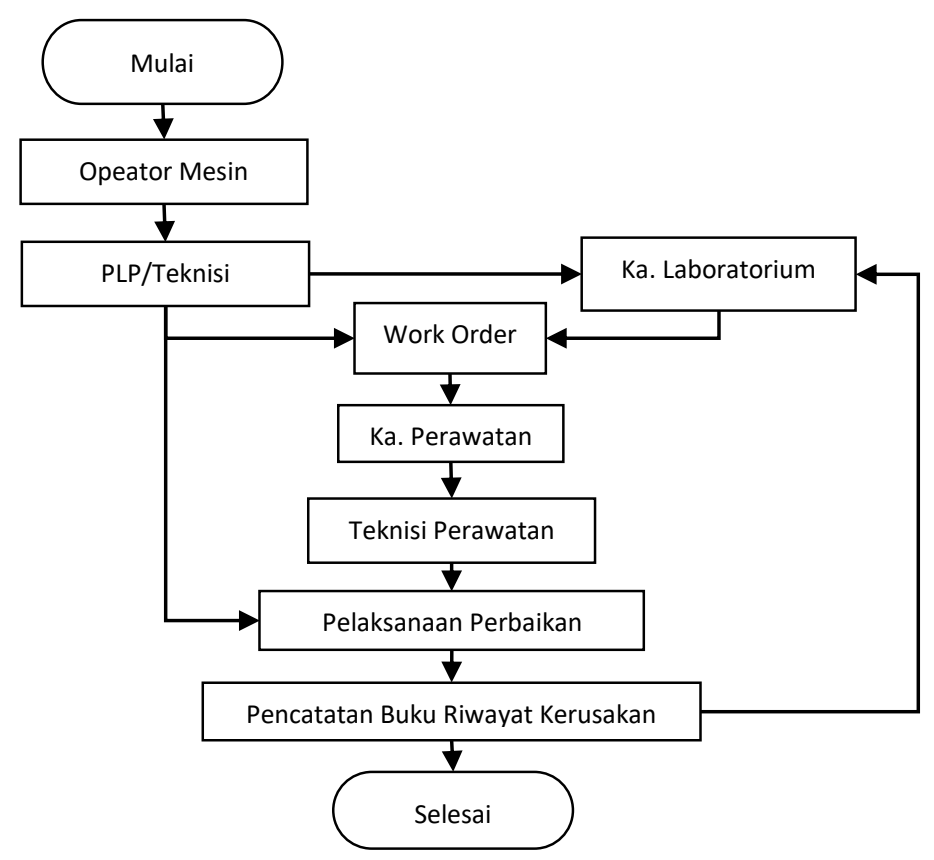

Gambar 2. Diagram Alir Perawatan Perbaikan

Permasalahan yang pada perbaikan tersebut akan dilakukan setelah adanya permintaan perbaikan oleh kepala laboraotium dan staf produksi melalui surat perintah kerja (WO) yang ditulis secara manual menggunakan buku WO yang telah disediakan. Terkadang staf produksi juga langsung melakukan perbaikan secara tersendiri tanpa menulis di buku WO. Setelah dilakukan perbaikan staf perawatan mendokumentasikan kegiatan tersebut ke dalam buku perawatan. Sehingga proses ini terkadang menjadi permasalahan karena data yang tersimpan tidak terjamin keberadaannya.

\section{HASIL DAN PEMBAHASAN}

3.1. Analisa Hasil Rancangan

Rancangan Sistem yang dibuat dilakukan dengan maksud agar kegiatan perawatan korektif yang telah dijalankan secara komputerisasi dan diharapkan membawa perubahan yang baik terhadap pelaksanaan kegiatan Laporan perawatan di Laboratorium Polmanbabel. Untuk mempermudah dalam pembuatan tampilan database ini, maka dibuatlah sket tampilan secara manual seperti yang ditunjukkan pada Gambar 3.

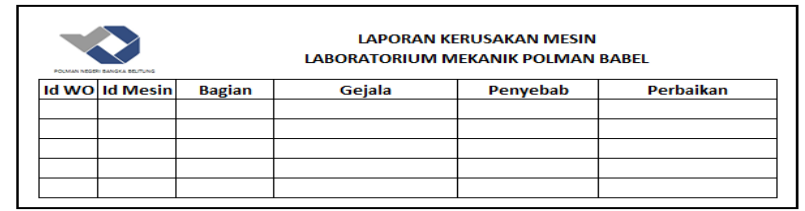

Gambar 3. Contoh Sket Manual Pembuatan Form Laporan Biaya

Sket ini kemudian direalisasikan kedalam bentuk-bentuk form tampilan sesungguhnya pada pembuatan program. Adapun tampilan yang diinginkan yaitu :

1. Tampilan Login dan menu utama,

2. Tampilan daftar WO dan penyebab kerusakan,

3. Tampilan Laporan kerusakan. 


\subsection{Ujicoba Rancangan}

Uji coba program merupakan tahap validasi untuk menguji program yang telah dibuat agar dapat diketahui apakah program tersebut dapat berfungsi dengan baik. Untuk melihat apakah program yang dibuat valid dan sesuai dengan harapan, maka dilakukan uji coba program dengan melihat tampilantampilan sebagai berikut :

\subsubsection{Tampilan Login Menu Utama}

Untuk memulai menjalankan program langkah pertama adalah klik login dan mengisi username dan pasword yang telah ditentukan kemudian klik OK, dapat dilihat pada Gambar 3.

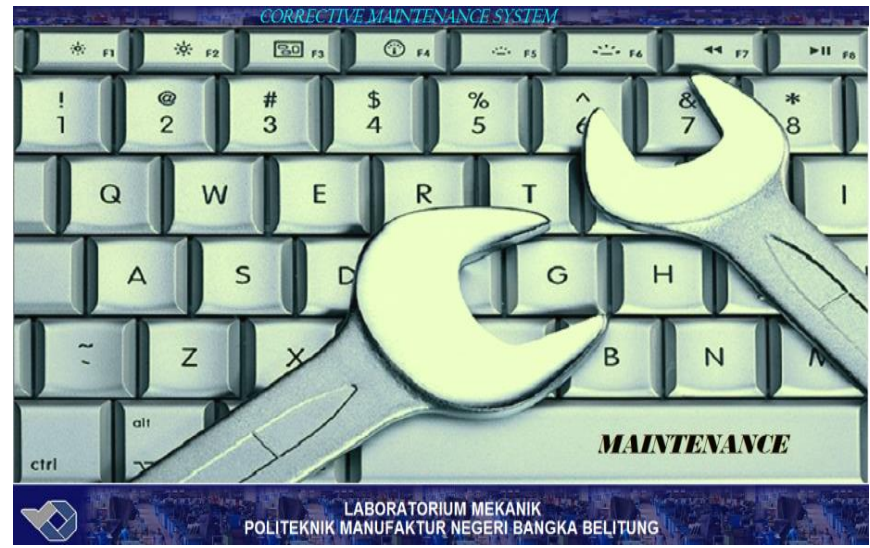

Gambar 4. Tampilan Login dan Menu Utama

\subsubsection{Tampilan Daftar WO dan Penyebab Kerusakan}

Pada tampilan ini pengguna bisa melihat daftar WO yang telah dilaksanakan dapat dilihat pada Gambar 5(a). WO merupakan tulang punggung sistem Computerized Maintenance Management Systems (CMMS) yang bisa menghasilkan, mencetak, dan perintah kerja yang lengkap [4].

Sedangkan tampilan untuk mencari kerusakan yang pernah terjadi sehingga pengguna bisa memperkirakan apa penyebab dan bagaimana perbaikannya ditunjukkan pada Gambar 5(b).

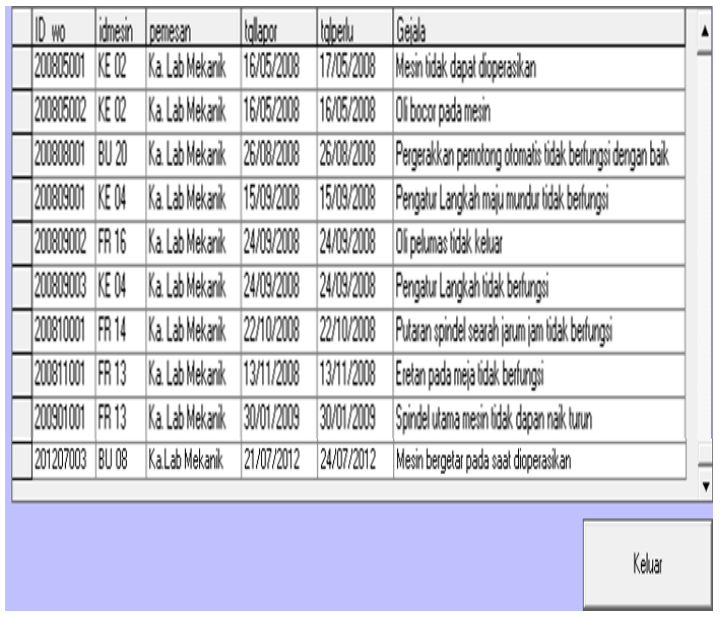

(a)

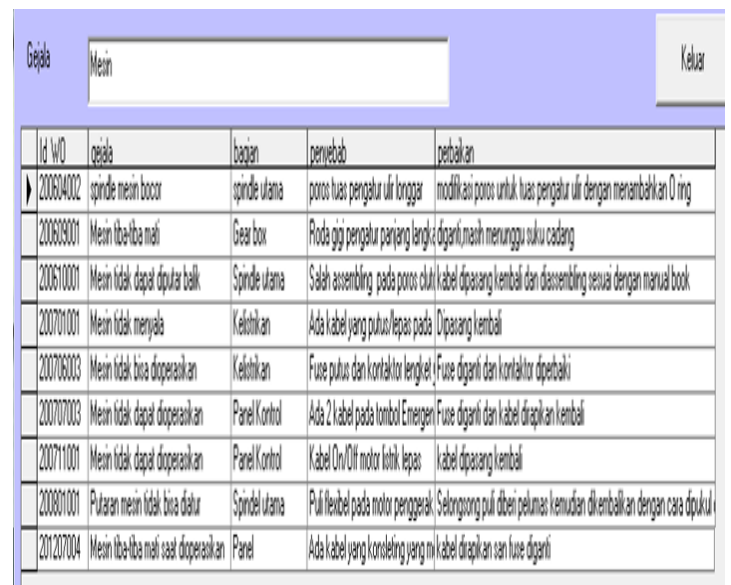

(b)

Gambar 5. (a) Tampilan Daftar WO, (b) Tampilan 


\begin{tabular}{|c|c|c|c|c|}
\hline Gepts & Mein & & & Keld: \\
\hline Wdwo & ogeds & bongen & neavedob & achotion \\
\hline 1 acoulu: & spinde nein boou & sinde vianta & 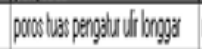 & 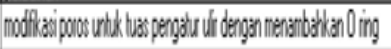 \\
\hline anomout & Mein tostbonsti & Gestow & Rodsojpengasupsizarglangl: & 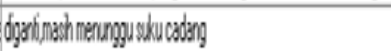 \\
\hline matcous & Mein fod dopa ofotat balk & Spronde usarila & 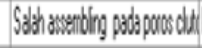 & 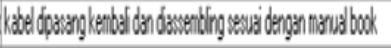 \\
\hline 2000000 & Mein fodek nendy & Kelsikikn & 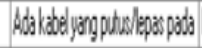 & 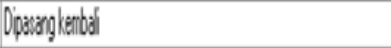 \\
\hline axpous & Meen od bis doperdikn & Kérisikn & 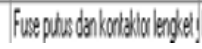 & 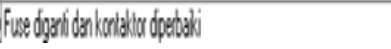 \\
\hline
\end{tabular}

Gambar 6. Tampilan Penyebab Kerusakan

\subsubsection{Tampilan Laporan Kerusakan}

menu laporan kerusakan yang bisa dilihat berdasarkan 1 (satu) WO, semua WO, bulanan dan juga tahunan. Tampilan ini juga bisa dicetak sesuai perintah, seperti yang ditunjukkan Gambar 6.

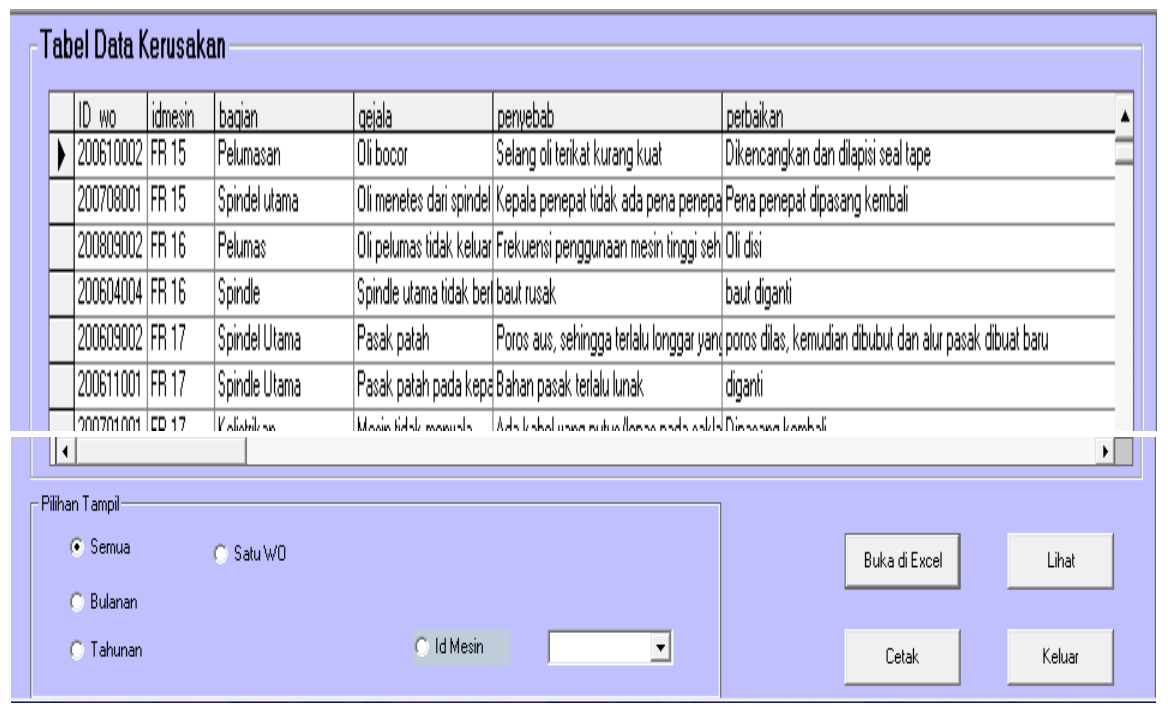

\section{SIMPULAN}

Gambar 7. Tampilan Laporan Kerusakan

Dari pembahasan yang dilakukan pada tahapan analisa dan uji coba dapat ditarik kesimpulan yaitu program database yang dibuat bisa dijalankan, hal ini dibuktikan dengan tampilan program yang muncul sesuai dengan perintah yang diberikan oleh pengguna (user), sehingga :

1. Riwayat kerusakan mesin dapat didokumentasikan dengan baik,

2. Pengguna dapat melihat data kerusakan untuk memperkirakan penyebab kerusakan mesin dari fenomena yang pernah terjadi.

\section{DAFTAR PUSTAKA}

[1] Raymond Murphy \& Jhon Martin, Computerized Preventive Maintenance,chapter 8,Maintenance Engineering handbook, USA: McGraw Hill Book Company Inc,1977.

[2] Corder, Antony, Teknik Manajemen Pemeliharaan, Jakarta: Erlangga, 1992.

[3] Mobley R. Keith, Maintenance Fundamentals, USA: Elsevier Buterworth- Heinemann, 2004.

[4] Bagadia, Kishan, Computerized Maintenance Management Systems Made Easy, New York: McGrawHill Companies, 2006. 